\title{
Breast MALT lymphomas: A clinicopathological and cytogenetic study of 9 cases
}

\author{
GIUSEPPINA LIGUORI $^{1}$, MONICA CANTILE ${ }^{1}$, MARGHERITA CERRONE $^{1}$, ELVIRA LA MANTIA ${ }^{1}$, \\ MAURIZIO DI BONITO ${ }^{1}$, FABRIZIO ZANCONATI ${ }^{2}$, MARIA PIA CURCIO ${ }^{1}$, GABRIELLA AQUINO ${ }^{1}$, \\ ANNA LA MURA ${ }^{3}$, ROSA GIANNATIEMPO $^{4}$, ANNAROSARIA DE CHIARA $^{1}$, ANGELA LOMBARDI $^{5}$, \\ GERARDO BOTTI $^{1}$, ANTONIO D'ANTONIO ${ }^{6}$, MICHELE CARAGLIA $^{5}$ and RENATO FRANCO ${ }^{1}$ \\ ${ }^{1}$ Pathology Unit, National Cancer Institute, Pascale Foundation, Naples; ${ }^{2}$ UCO Clinical Surgery, \\ University of Trieste, Trieste; ${ }^{3}$ Pathology Unit, Scafati Hospital, Salerno; ${ }^{4}$ Pathology Unit, \\ Villa Betania Hospital; ${ }^{5}$ Department of Biochemistry and Biophysics, Second University of Naples, Naples; \\ ${ }^{6}$ Department of Pathological Anatomy and Oncology, A.O.U. 'San Giovanni di Dio e Ruggi d'Aragona', Salerno, Italy
}

Received March 13, 2012; Accepted May 8, 2012

DOI: $10.3892 /$ or.2012.1942

\begin{abstract}
Primary breast mucosa-associated lymphoid tissue (MALT) lymphomas are uncommon and restricted diagnostic criteria should be used to exclude breast involvement by systemic lymphomas. The molecular pathogenesis of primary breast MALT lymphomas is not clear because of the rarity of the disease. Generally the molecular studies of MALT lymphoma in extranodal sites have shown the presence of different chromosomal aberrations, mutually exclusive with substantial differences in their frequency relatively to topographic localization. Few cases of breast MALT lymphomas in the literature have been assessed for MALT lymphoma-associated translocations and BCL10 expression, underlying their rarity in primary breast MALT lymphomas. In our study, we analyzed a series of nine cases of primary breast MALT lymphomas. FISH results showed evidence of MALT1 gene rearrangements in four primary breast lymphomas, in particular three cases with $\mathrm{t}(11 ; 18)(\mathrm{q} 21 ; \mathrm{q} 21)$ and one case with $\mathrm{t}(14 ; 18)(\mathrm{q} 32 ; \mathrm{q} 21)$. In addition, BCL10 gene rearrangement was not observed. There was no evidence of BCL10 gene translocation in any of the neoplasms assessed. Our data indicate that MALT1 gene rearrangements are not rare in primary breast MALT lymphoma in contrast with results of previous series. Finally, $t(11 ; 18)$ has been observed to be significantly associated with high intensity cytoplasmic BCL10 expression underlying cross-talk between MALT1 and BCL10 pathways in the pathogenesis of MALT lymphomas.
\end{abstract}

Correspondence to: Professor Michele Caraglia, Department of Biochemistry and Biophysics, Second University of Naples, Via Costantinopoli 16, 80138 Naples, Italy

E-mail: michele.caraglia@unina2.it or michele.caraglia@alice.it

Key words: breast disease, mucosa-associated lymphoid tissue lymphoma, FISH analysis

\section{Introduction}

Malignant lymphomas observed in the breast are most commonly non-Hodgkin lymphomas. They could be primary breast lymphoma (PBL) or most frequently a sign of systemic disease $(1,2)$. The PBL represent $0.38-0.70 \%$ of all non-Hodgkin lymphomas (NHL), 1.7-2.2\% of all extra nodal NHL and only $0.04-0.5 \%$ of all breast cancer (1-3). The WHO criteria for the diagnosis of PBL are clinicopathological demonstration of lymphomatous infiltration within breast tissue with or without involvement of axillary lymph nodes, but in absence of systemic disease $(1,4)$. The most common histotypes of PBL are diffuse large B-cell lymphoma and extra nodal marginal zone B-cell lymphoma of mucosa-associated lymphoid tissue MALT-type (MALT lymphomas) $(1,2)$.

The molecular studies of MALT lymphoma in extra nodal sites have shown the presence of different chromosomal translocations that appear to be mutually exclusive with substantial differences in their frequency in relation to extra nodal anatomic sites. These translocations include the $\mathrm{t}(11 ; 18)(\mathrm{q} 21 ; \mathrm{q} 21), \mathrm{t}(14 ; 18)$ $(\mathrm{q} 32 ; \mathrm{q} 21), \mathrm{t}(1 ; 14)(\mathrm{q} 22 ; \mathrm{q} 32)$, and the most recently described, $\mathrm{t}(3 ; 14)(\mathrm{p} 14.1 ; \mathrm{q} 32)(5-7)$. These translocations result in the production of a chimeric protein (API2-MALT1) or in BCL10, MALT1, FOXP1 genes over expression, because of direct control of IgH promoter (8-10).

The purpose of this study is the evaluation of chromosomal rearrangements $\mathrm{t}(11 ; 18)(\mathrm{q} 21 ; \mathrm{q} 21), \mathrm{t}(14 ; 18)(\mathrm{q} 32 ; \mathrm{q} 21), \mathrm{t}(1 ; 14)$ (q22;q32) and BCL10 expression in a series of nine cases of primary breast MALT lymphomas.

\section{Materials and methods}

Clinical information. Cases were selected from the pathological files of the Cardarelli Hospital and National Tumor Institute Pascale, Naples, and University of Trieste, from January 1993 to December 2010. The WHO criteria to establish the diagnosis of PBL have been strictly applied. Thus cases included in our study are characterized by the following 
Table I. Immunohistochemical antibodies.

\begin{tabular}{|c|c|c|c|c|c|}
\hline Antigen clone & Source & Dilution & Reactivity & Threshold & Internal control \\
\hline $\begin{array}{l}\text { CD20 } \\
\text { (clone L-26) }\end{array}$ & Dako & $1: 100$ & Positive/negative & $\begin{array}{l}\text { Any positive } \\
\text { neoplastic cells }\end{array}$ & $\begin{array}{l}\text { Reactive } \\
\text { lymphocyte }\end{array}$ \\
\hline $\begin{array}{l}\text { CD10 } \\
\text { (clone56C6) }\end{array}$ & Novocastra & $1: 10$ & Positive/negative & $\begin{array}{l}\text { Any tumoral cell } \\
\text { positive }\end{array}$ & GC* B cells \\
\hline $\begin{array}{l}\text { Bcl6 } \\
\text { (clonePG-B6p) }\end{array}$ & Dako & $1: 10$ & Positive/negative & $>10 \%$ neoplastic cells & GC* B cells \\
\hline $\begin{array}{l}\text { CK } \\
\text { (clone AE1/AE3) }\end{array}$ & Dako & $1: 50$ & Positive/negative & $\begin{array}{l}\text { Any positive } \\
\text { neoplastic cells }\end{array}$ & $\begin{array}{l}\text { Breast } \\
\text { epithelial cell }\end{array}$ \\
\hline Bcl10 & Dako & $1: 200$ & Positive/negative & $>10 \%$ neoplastic cells & $\begin{array}{l}\text { Reactive } \\
\text { lymphocyte }\end{array}$ \\
\hline CD3 & Dako & $1: 25$ & Positive/negative & Any tumoral cell & $\begin{array}{l}\text { Reactive } \\
\text { lymphocyte }\end{array}$ \\
\hline CD5 & Novocastra & $1: 50$ & Positive/negative & $>10 \%$ positive cells & $\begin{array}{l}\text { Reactive } \\
\text { lymphocyte }\end{array}$ \\
\hline
\end{tabular}

features: i) histologically the lymphomatous infiltrate should demonstrate a close relationship with the breast parenchyma with or without ipsilateral axillary lymph node involvement; ii) no evidence of systemic disease after staging; iii) imaging studies clearly identified the neoplasm to be within the breast in absence of other localization. Clinical information was recovered from clinical files. A total of 9 cases of MALT-like lymphomas were identified.

Specimens had been routinely fixed and processed. Haematoxylin and eosin (H\&E) stained sections and appropriate immunohistochemical staining were performed in order to confirm diagnosis of MALT-like PBL (Table I). As part of this study, additional immunostaining has been performed using antibodies specific for BCL10.

Stained sections were evaluated by four different pathologists (R.F., A.D., M.D.B., G.B.) using uniform criteria. Discrepancies were resolved through simultaneous evaluation and discussion of the results. Single-marker expression was recorded as negative/positive and high/low level, after consideration of the expression in reactive compared with tumoral cells and the specific cut-off of each marker. As proposed, cytoplasmic BCL10 expression was scored as strong when it was similar to tonsil centroblast positivity, moderate when similar to centrocyte positivity, and weak/absent when similar to tonsil mantle-zone positivity. Nuclear positivity has been also recorded (11).

Fluorescent in situ hybridization study. Tissue array sections from paraffin-embedded tissue were heated for $4 \mathrm{~h}$ at $62^{\circ} \mathrm{C}$ and immediately deparaffinized in two rinses of $100 \%$ xylene for $10 \mathrm{~min}$ each. The slides were then treated with $0.3 \mathrm{M}$ sodium chloride and $0.03 \mathrm{M}$ sodium citrate for $20 \mathrm{~min}$ at $80^{\circ} \mathrm{C}$, and with $0.05 \mathrm{mg} / \mathrm{ml}$ proteinase for $10 \mathrm{~min}$ at $37^{\circ} \mathrm{C}$. For $\mathrm{t}(11 ; 18)$ (q21;q21) detection, we used LSI API2/MALT1 $\mathrm{t}(11 ; 18)$ (q21;q21) dual-colour, dual-fusion translocation probe, and for $\mathrm{t}(14 ; 18)(\mathrm{q} 32 ; \mathrm{q} 21)$ we used LSI IGH/MALT1 t(14;18)(q32;q21) dual-colour, dual-fusion translocation probe. For detection of BCL10 translocation BCL10 FISH DNA Probe, Split Signal, and Histology FISH kit (Dako) were used. The cut-off value for the diagnosis of rearrangement involving IGH and MALT1 was $5.3 \%$, which is above the mean percentage of cells with a false positive signal plus $3 \mathrm{SD}$, as assessed in tissue from reactive tonsils present in TMA. Moreover, IGH dual-colour break-apart rearrangement probes (Vysis Inc., Downers Grove, IL, USA) were applied to cells of all $\mathrm{t}(14 ; 18)(\mathrm{q} 32 ; \mathrm{q} 21)$-positive lymphomas to confirm the translocation.

The Spectrum Green-labelled LSI IGVH probe covers the entire IGH variable region, while the Spectrum Orangelabelled probe lies completely within the IGH locus. As a result of this probe design, any translocation with a breakpoint at the $\mathrm{J}$ segments, or within switch sequences, should produce separate orange and green signals. Additionally, FISH with centromerespecific probes for chromosome 18 (Vysis) was performed in all cases. The appropriate probe mix $(10 \mathrm{ml})$ was applied to the tissue sections and covered with a coverslip. Both probe and target DNA were simultaneously denatured at $75^{\circ} \mathrm{C}$ for $5 \mathrm{~min}$ and incubated overnight at $37^{\circ} \mathrm{C}$ using the Hybrite System. Post-hybridization washes were performed according to the 'rapid wash protocol' provided by Vysis. Slides were counterstained with 406-diamidino-2-phenylindole 2HCl (DAPI). FISH was performed according to the manufacturer's instructions (Vysis). FISH data were collected using an Olympus BX 61 fluorescence microscope equipped with a cooled black-andwhite camera controlled by the associated software (Olympus, Italy).

Statistical analysis. The Pearson's $\chi^{2}$ test was used where appropriate, to establish whether there were any relationships between the frequencies of different markers included in this study. Differences were considered to be significant for values of $\mathrm{P}<0.05$. All statistical analyses were performed using the SPSS 98 v.12 program. 

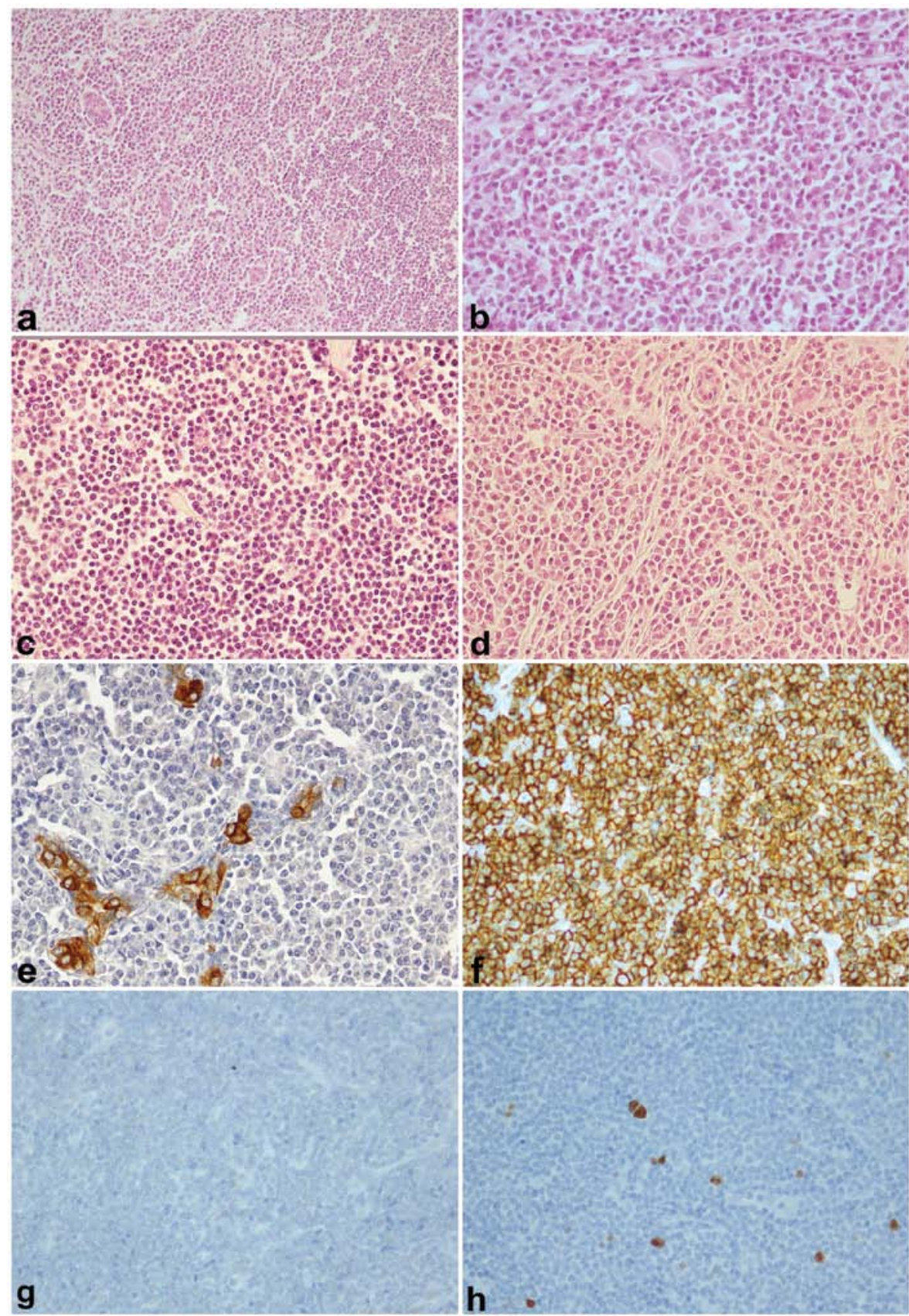

Figure 1. (a) Epithelial islands in a diffuse pattern of lymphoma proliferation, $x 10$, hematoxylin and eosin stain; (b) Lymphoma proliferation surrounds epithelial ducts, x40; (c) Monocytoid differentiation of MALT lymphoma, x40; (d)Plasmocytoid differentiation in MALT lymphoma, x40; (e) CK immunostaining, $\mathrm{x} 40$, in trapped duct cells by lymphoma; (f) CD20 immunostaining, x40, diffuse neoplastic cells positivity; (g) BCL6 immunostaining, x40, BCL6 negativity in MALT lymphoma; (h) Ki67 immunostaining, x40, low proliferation index of lymphoma.

\section{Results}

Clinical features. The main clinicopathological data are reported in the Table II. All patients were female, with mean age of 72 years (range: 39-93). In 6 cases right breast was involved. Mean time of follow-up was 51 months (range: 33-65) and at the end of follow-up, 2 patients were alive, 6 alive with disease and 1 dead from disease.

Histological findings. All nine cases of MALT lymphoma had a diffuse or vaguely nodular growth pattern. We have identified three types of lymphoid cells: i) small to medium lymphoma cells with irregular nuclear contours, inconspicuous nucleoli and pale-staining cytoplasm (centrocyte-like cells), prevalent in all cases; ii) small lymphoid cells with round nuclei, clumped chromatin and sparse cytoplasm, some with prominent plasmacytic differentiation admixed with mature plasma cells; iii) lymphoid cells with abundant pale or clear cytoplasm resembling monocytoid cells. These elements are present in a variable number in all cases. Lymphoepithelial lesions were present but were not prominent. Transformed lymphocytes resembling centroblasts or immunoblasts were present in all cases, but rarely formed small clusters or confluent sheets. Lymphoid follicle with reactive germinal centre was also present in breast tissue in two cases. Mitotic activity was low and necrosis areas were not observed (Fig. 1). 
Table II. Main clinicopathological data.

\begin{tabular}{lcccccccc}
\hline Case no. & Gender & Age & Site & BCL10 IHC & $\mathrm{t}(11 ; 18)$ & $\mathrm{t}(14 ; 18)$ & $\mathrm{t}(1 ; 14)$ & Status \\
\hline 1 & $\mathrm{~F}$ & 71 & $\mathrm{R}$ & - & - & - & - & AWD \\
2 & $\mathrm{~F}$ & 82 & $\mathrm{R}$ & $1+$ & - & - & - & AWD \\
3 & $\mathrm{~F}$ & 93 & $\mathrm{R}$ & - & + & - & - & AWD \\
4 & $\mathrm{~F}$ & 73 & $\mathrm{R}$ & - & - & - & - & Alive \\
5 & $\mathrm{~F}$ & 74 & $\mathrm{~L}$ & - & - & - & - & Dead \\
6 & $\mathrm{~F}$ & 71 & $\mathrm{~L}$ & $2+$ & - & - & - & AWD \\
7 & $\mathrm{~F}$ & 72 & $\mathrm{R}$ & $2+$ & + & - & - & AWD \\
8 & $\mathrm{~F}$ & 73 & $\mathrm{~L}$ & $2+$ & + & - & - & AWD \\
9 & $\mathrm{~F}$ & 39 & $\mathrm{R}$ & - & - & + & - & Alive \\
\hline
\end{tabular}

F, female; R, right breast; L, left breast; AWD, alive with disease.

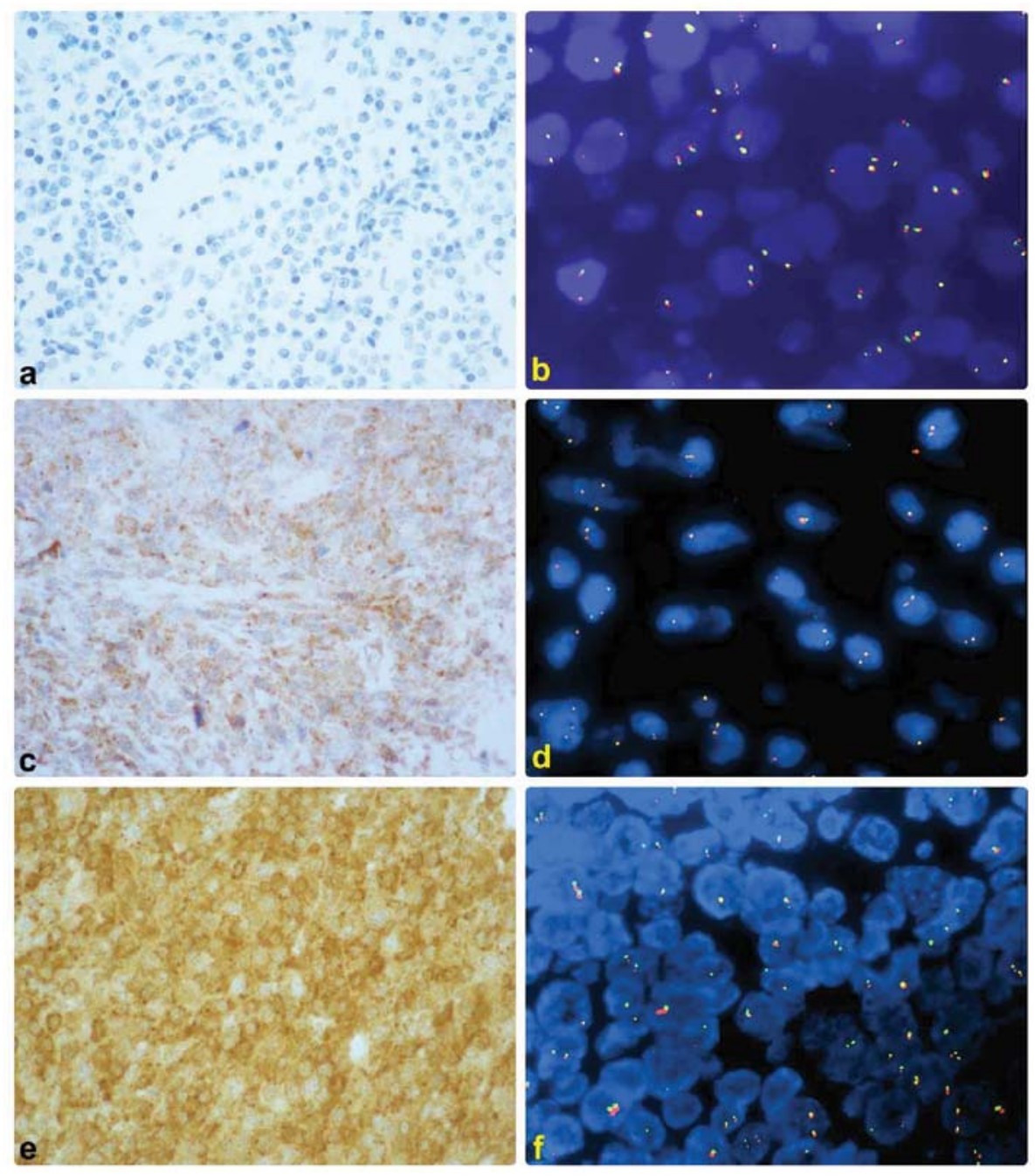

Figure 2. (a) Negative BCL10 immunostaining, x40; (c) Moderate BCL10 immunostaining, x40; (e) Intense BCL10 immunostaining, x40; (b, d and f) FISH $\mathrm{t}(1 ; 14), \mathrm{x} 100$, integrity of BCL10 genes signals in all cases.

Immunohistochemical findings. Immunohistochemical results are summarized in Table II. Lymphoma cells express pan B-lymphocyte antigens CD20 and CD79a in all cases and 8 show $\kappa$ light chain restriction. CD43 was expressed in $8 / 9$ cases, while CD5, CD10, BCL6 and CD10 that were usually negative. BCL10 was positive with cytoplasmic high intensity in 4 cases and negative in 5 . No nuclear positive case was observed (Fig. 2). 
FISH analysis. $\mathrm{t}(11 ; 18)(\mathrm{q} 21 ; \mathrm{q} 21)$ was present in 3 cases and $\mathrm{t}(14 ; 18)(\mathrm{q} 32 ; \mathrm{q} 21)$ in one case. There was no evidence of $(1 ; 14)$ (q22;q32) in any of the lymphoma assessed (Fig. 2).

Statistical analysis. Only association between $\mathrm{t}(11 ; 18)$ and high intensity cytoplasmic expression of BCL10 $(\mathrm{P}=0.046)$ was observed.

\section{Discussion}

MALT type extra nodal marginal zone B-cell lymphoma (MALT lymphoma) represents $<10 \%$ of all B-cell lymphomas (1). They are most frequent in the gastrointestinal tract, salivary glands, ocular adnexa, lungs, thyroid and breast (8). Due to the lack of native lymphoid tissue in these organs, a chronic inflammatory stimulus or an autoimmune disease can generate mucosa-associated lymphoid tissue from which a MALT lymphoma could arise (1,2,3,5-9). Histologically MALT lymphomas show a case-to-case variability in the neoplastic cytotype. Usually we have observed small cell lymphomas constituted by centrocyte-like cells with irregular nuclei, monocytoid B-cell with pale to clear cytoplasm with round nuclei and more rarely plasmacytoid cells. The different histological features of the tumor cells do not impact on clinical prognosis (9). Generally MALToma have an indolent behavior and recurrence can occur after many years also in other extra nodal sites. Moreover, in some cases a progression to diffuse large B-cell lymphoma may occur $(1,9)$. In particular in a recent work primary breast MALT lymphomas seem to have a more indolent behavior in respect to other PBLs (12).

The molecular events underlying the origin of a mucosaassociated lymphoid tissue (MALT) lymphoma and their progression and prognosis are largely unknown. However, some chromosomal translocations have been identified in a subset of MALT lymphomas, including the $\mathrm{t}(11 ; 18)(\mathrm{q} 21 ; \mathrm{q} 21)$, $\mathrm{t}(14 ; 18)(\mathrm{q} 32 ; \mathrm{q} 21), \mathrm{t}(1 ; 14)(\mathrm{p} 22 ; \mathrm{q} 32)$, and $\mathrm{t}(3 ; 14)(\mathrm{p} 14.1 ; \mathrm{q} 32)$. These translocations are responsible for deregulation of MALT1, BCL10 and FOXP1 genes that cooperate in the NFKB anti-apoptotic pathway (13). Particularly, t(11;18)(q21;q21) and $\mathrm{t}(14 ; 18)(\mathrm{q} 32 ; \mathrm{q} 21)$ generate chimeric transcripts of MALT1 gene respectively with the API2 and IgH gene, whereas $t(1 ; 14)$ (p22;q32) causes aberrant BCL10 expression with nuclear localization (5-9).

In addition, nuclear BCL10 expression also occurs in MALT lymphomas without $\mathrm{t}(1 ; 14)(\mathrm{p} 22 ; \mathrm{q} 32)$, suggesting an important role for BCL10 in lymphoma development (14-17). All these abnormalities also appear to be mutually exclusive and their frequency correlates with the anatomic site. The translocation $(11 ; 18)$ is frequently described in gastrointestinal and pulmonary sites in contrast with presence of $t(14 ; 18)$ in ocular adnexa, skin and salivary gland $(1-7,10,11)$. Different series regarding the most common extra nodal sites of MALT lymphomas have been screened for the presence of the most common translocations involving MALT1 gene and BCL10 expression with relation to progression of disease or prognosis $(11,14-18) . \mathrm{t}(11 ; 18)(\mathrm{q} 21 ; \mathrm{q} 21)$ is associated with advanced gastric MALT-lymphoma that expresses nuclear BCL10. Moreover, nuclear expression of BCL10 or nuclear factor $\kappa \mathrm{B}$ predicts Helicobacter pylori-independent status of early-stage, highgrade gastric mucosa-associated lymphoid tissue lymphomas
(17). Moreover, nuclear BCL10 expression characterizes a group of ocular adnexa MALT lymphomas with shorter failurefree survival (11).

While the frequency of these translocations has been studied in the most common extra nodal sites, their presence has not been well characterized in the breast presumably because these neoplasms are very infrequent. In a previous study, Talwakar et al (18) studied eight cases of primary MALT breast lymphoma and 14 cases of primary breast diffuse large B-cell lymphoma for MALT1 gene rearrangements through FISH and for BCL10, NF- $\mathrm{KB}$ p65, p50 using immunohistochemical methods. None of the cases showed MALT1 gene rearrangements and NF- $\mathrm{\kappa B}$ activation was not demonstrated. Similar results were obtained by Streubel et al (7) in five additional cases of breast MALT lymphoma assessed for the $\mathrm{t}(11 ; 18)$ and $\mathrm{t}(14 ; 18)$ and by Mulligan et al in a small series of PBL MALT lymphomas assessed for MALT1 gene rearrangement (19). All these authors concluded that MALT1 gene rearrangements are absent or rare in primary breast MALT lymphoma compared to other extra nodal MALToma. In our series both the $t(11 ; 18)$ and $t(14 ; 18)$ were observed. Our results showed evidence of MALT1 gene rearrangements in four PBL: $\mathrm{t}(11 ; 18)(\mathrm{q} 21 ; \mathrm{q} 21)$ was observed in 3 cases and $\mathrm{t}(14 ; 18)(\mathrm{q} 32 ; \mathrm{q} 21)$ in one case. The expression of BCL10 was only cytoplasmic in 4 cases, with low/moderate intensity, while nuclear expression was not observed. No association with chromosomal aberration was observed.

In conclusion, our data indicated that MALT1 gene rearrangements are not rare in primary breast MALT lymphoma, in contrast with results of previous series, involving mainly $\mathrm{t}(11 ; 18)(\mathrm{q} 21 ; \mathrm{q} 21)$.

\section{References}

1. Tavassoli FA and Devilee P: Malignant lymphoma and metastatic tumours. In: World Health Organization Classification of Tumours: Pathology and Genetics. Tumors of the Breast and Female Genital Organs. IARC (ed): Lyon, pp107-109, 2003.

2. Brogi E and Harris NL: Lymphomas of the breast: pathology and clinical behaviour. Semin Oncol 26: 357-364, 1999.

3. Avenia N, Sanguinetti A, Cirocchi R, Bistoni G, Trastulli S, D'Ajello F, Barberini F, Cavallaro G, Rulli A, Sidoni A, et al: Primary breast lymphomas: a multicentric experience. World J Surg Oncol 8: 53, 2010.

4. Wiseman C and Liao KT: Primary lymphoma of the breast. Cancer 29: 1705-1712, 1972.

5. Ye $\mathrm{H}$, Liu $\mathrm{H}$ and Attygalle A: Variable frequencies of $\mathrm{t}(11 ; 18)$ (q21;q21) in MALT lymphomas of different sites: significant association with CagA strains of $H$. pylori in gastric lymphoma. Blood 102: 1012-1018, 2003.

6. Streubel B, Simonitsch-Klupp I and Mullauer L: Variable frequencies of MALT lymphoma-associated genetic aberrations in MALT lymphomas of different sites. Leukemia 18: 1722-1726, 2004.

7. Streubel B, Vinatzer U and Lamprecht A: $\mathrm{t}(3 ; 14)(\mathrm{p} 14.1 ; \mathrm{q} 32)$ involving IGH and FOXP1 is a novel recurrent chromosomal aberration in MALT lymphoma. Leukemia 9: 652-658, 2005.

8. Lucas PC, Yonezumi M and Inohara N: Bcl10 and MALT1, independent targets of chromosomal translocation in Malt lymphoma, cooperate in a novel NF-kappa B signalling pathway. J Biol Chem 276: 19012-19019, 2001.

9. Isaacson PG and Du MQ: MALT lymphoma: from morphology to molecules. Nat Rev Cancer 4: 644-653, 2004.

10. Nakagawa M, Hosokawa Y and Yonezumi M: MALT1 contains nuclear export signals and regulates cytoplasmic localization of BCL10. Blood 106: 4210-4216, 2005.

11. Franco R, Camacho FI and Caleo A: Nuclear bcl10 expression characterizes a group of ocular adnexa MALT lymphomas with shorter failure-free survival. Mod Pathol 19: 1055-1067, 2006. 
12. Martinelli G, Ryan G, Seymour JF, Nassi L, Steffanoni S, Alietti A, Calabrese L, Pruneri G, Santoro L, Kuper-Hommel M, et al: Primary follicular and marginal-zone lymphoma of the breast: clinical features, prognostic factors and outcome: a study by the International Extranodal Lymphoma Study Group. Ann Oncol 20: 1993-1999, 2009.

13. Liu H, Ye H, Dogan A, Ranaldi R, et al: $\mathrm{T}(11 ; 18)(\mathrm{q} 21 ; \mathrm{q} 21)$ is associated with advanced mucosa-associated lymphoid tissue lymphoma that expresses nuclear BCL10. Blood 98: 1182-1187, 2001.

14. Ye H, Dogan A and Karran L: BCL10 expression in normal and neoplastic lymphoid tissue. Nuclear localization in MALT lymphoma. Am J Pathol 157: 1147-1154, 2000.

15. Yeh KH, Kuo SH and Chen LT: Nuclear expression of BCL10 or nuclear factor kappaB helps predict Helicobacter pylori-independent status of low-grade gastric mucosa-associated lymphoid tissue lymphomas with or without $\mathrm{t}(11 ; 18)(9 \mathrm{q} 21 ; \mathrm{q} 21)$. Blood 106: 1037-1041, 2005.
16. Sagaert X, Laurent M and Baens M: MALT1 and BCL10 aberrations in MALT lymphomas and their effect on the expression of BCL10 in the tumor cells. Mod Pathol 19: 225-232, 2006.

17. Kuo SH, Chen LT, Yeh KH and Wu MS: Nuclear expression of BCL10 or nuclear factor kappa B predicts Helicobacter pylori-independent status of early-stage, high-grade gastric mucosa-associated lymphoid tissue lymphomas. J Clin Oncol 22: 3491-3497, 2004.

18. Talwalkar SS, Valbuena JR, Abruzzo LV and Admirand JH: MALT1 gene rearrangements and NF-kappaB activation involving p65 and p50 are absent or rare in primary MALT lymphomas of the breast. Mod Pathol 19: 1402-1408, 2006.

19. Mulligan S, Hu P, Murphy A, Han J, Tam M, Lin P, Konopley S and Lennon PA: Variations in MALT1 gene disruptions detected by FISH in 109 MALT lymphomas occurring in different primary sites. J Assoc Genet Technol 37: 76-79, 2011. 